\title{
Diagnosis and Therapeutic Management of Parathyroid Cysts
}

\author{
Jean-Baptiste Finel, Stéphanie Mucci, Frédéric Branger, Aurélien Venara, Laure Blanchard, \\ Antoine Hamy ${ }^{*}$ \\ Department of Digestive and Endocrine Surgery, University Hospital, Angers, France \\ Email: *anhamy@chu-angers.fr
}

Received July 21, 2012; revised August 25, 2012; accepted September 7, 2012

\begin{abstract}
Objectives: The parathyroid cysts (PCs) are rare and their diagnosis and therapeutic management are not clearly established. The aim of the study was to evaluate the characteristics of parathyroid cysts. Methods and Materials: Twenty-five patients with PC were included in this retrospective study. The PCs were discovered as follows: cervical mass $(n=18)$, screening for other pathologies $(n=7)$. Intracystic parathyroid hormone determination was performed in 6 cases. Results: Eight patients presented a hyperparathyroidism. Mean cyst size was $21.1 \mathrm{~mm}$ (ext $4-70 \mathrm{~mm}$ ) by $19.8 \mathrm{~mm}(5-45 \mathrm{~mm}$ ). Twenty four cysts were cervical (resection by cervicotomy), and one was mediastinal (resection by sternotomy). In addition to the resection of the PC, 3 adenomas, 1 hyperplasia of the parathyroid glands, 14 benign thyroid diseases and 4 papillary carcinomas were recognized and treated during the cervicotomies. Conclusion: The diagnosis of PC is uncommon and must be based primarily on the study of the cyst liquid obtained by percutaneous puncture (intracystic parathyroid hormone measurement). True PCs are non functional.
\end{abstract}

Keywords: Hyperparathyroidism; Cystic Parathyroid; Intact Parathyroid Hormone

\section{Introduction}

Parathyroid cysts are rare and represent $1 \%-3.3 \%$ of parathyroid pathology [1]. They were present in $2.8 \%$ of subjects in a set of autopsies [2]. In 1999, 250 cases were described in the literature of which 94 cases were mediastinal. They have a variable presentation with local or hormonal effects. Their treatment is most often surgical (resection by the cervical or thoracic route). However in certain cases, newly developed ultrasound guided fine needle aspiration and sclerosing injections can be used in their management $[3,4]$. We report a unicentric sample of twenty-five patients managed in the department of General \& Endocrine Surgery which allowed us to compare our results and recommendations with those published in the literature.

\section{Patients and Methods}

This retrospective study reviews the activity of the department of General \& Endocrine surgery (University Hospital of Angers) between the 1st of January 1986 and the 31st of September 2011. It consists of 25 patients, 19 females and 6 males with an average age of 51.3 years (range: 22 - 83). The patients presented due to a cervical

"Corresponding author. mass in 18 cases and general health check-ups (osteoporosis, obesity, HTA) in 7 cases.

Functional parathyroid cyst (FPC) is defined as a biochemical primary hyperparathyroidism diagnosed before surgery. In contrast, non functional parathyroid cyst (NFPC) was considered in patients with normal level of PTH and calcemia before surgery.

An ultrasound was performed for all patients. For 11 patients a scintigraphy was performed.

The parameters studied were the anatomical aspect, the clinical characteristics and histological analysis of the lesions.

\section{Results}

Among 25 patients with cystic parathyroid lesions, 20 (80\%) had non functional cystic parathyroid lesions (NFPC) and 5 (20\%) had functional parathyroid cyst lesions (FPC).

Among these 25 parathyroid cysts, 3 lesions (2 NFPCs and 1 FPC) were associated with parathyroid adenomas and 1 with parathyroid hyperplasia.

Histological analysis revealed 4 cyst adenomas and all of them were FPC. All of the 20 NFPCs were true cysts parathyroid. The mean age is 51.3 years $(22-83)$. The principal localisation is inferior $\mathrm{n}=15(63 \%)$ and left $\mathrm{n}=$ 14 (58\%). 
Twenty-four (96\%) cysts were cervical and one cyst was mediastinal. The cysts size on average $27 \mathrm{~mm}$ (range = $5-70 \mathrm{~mm})$ by $22 \mathrm{~mm}(5-45 \mathrm{~mm})$. Hyperparathyroidism (serum parathyroid hormone greater than $50 \mathrm{ng} / \mathrm{ml}$ ) was recorded in 8 patients.

Six patients underwent ultrasound guided fine needle aspiration under local anaesthetic to drain their cyst. The intact PTH measurement in the cyst fluid ranged from 53 to $2661 \mathrm{pg} / \mathrm{ml}$ parathyroid (normal serum PTH is less than 50). One patient had a first aspiration aimed purely at alleviating their symptoms (without the measurement of intracystic PTH). The cyst recurred and a new aspiration was carried out with the measurement of PTH in the cystic fluid (level of $685 \mathrm{pg} / \mathrm{ml}$ ).

Eighteen patients had a single parathyroid cyst associated with other cervical pathology originating, in 4 cases, from the other parathyroids ( 3 adenomas and 1 hyperplasia) and, in 14 cases, from the thyroid (euthyroid on biochemical testing).

In total 5 patients had more than one parathyroid gland excised ( 1 hyperplasia, 3 adenomas and 1 normal parathyroid) and 14 thyroidectomies were carried out (4 total, 10 subtotal) with associated parathyroidectomy.

The interventions were carried out by cervicotomy in 21 , by first focused in 3 cases and sternotomy in 1 case. In the later case the (asymptomatic) patient had initially presented with a bronchogenic cyst.

Corresponding pathologies which were encountered were: 1 case of parathyroid hyperplasia; 3 parathyroid adenomas; 10 cases of benign thyroid disease and 4 papillary carcinomas. All the interventions were uncomplicated without morbidity in particular without recurrence. A summary of our observations is given in Table $\mathbf{1 .}$

Table 1. Characteristics and surgical results of patients with parathyroid cyst.






\begin{tabular}{|c|c|c|c|c|c|c|c|c|}
\hline \multicolumn{9}{|c|}{ Continued } \\
\hline $39 / \mathrm{F}$ & Goiter & No & US & R PIV & 10 & Surgery & NFPC & N/NA \\
\hline $49 / \mathrm{F}$ & Cervical mass & No & US & L PIII & 50 & Surgery & NFPC & N/NA \\
\hline $28 / \mathrm{F}$ & Goiter & No & US & R PIII & 5 & Surgery & NFPC & N/NA \\
\hline $68 / \mathrm{F}$ & Osteoporosis & Yes & US & L PIV & 15 & $\begin{array}{l}\text { Surgery (2 } \\
\text { glands) }\end{array}$ & NFPC + adenoma & $>55 / \mathrm{NA}$ \\
\hline $59 / \mathrm{F}$ & $\begin{array}{l}\text { Asymptomatic } \\
\text { thyroid nodule }\end{array}$ & No & US & L PIII & 40 & Surgery & NFPC & N/NA \\
\hline
\end{tabular}

N normal, NA not assessed, L PIII left inferior parathyroid gland, L PIV left superior parathyroid gland, R PIII right inferior parathyroid gland, US ultrasound, Sc scintigraphy. R PIV right superior parathyroid gland, FPC functional parathyroid cyst, NFPC non functional parathyroid cyst. $10<\mathrm{N}<55$ pg/ml. ${ }^{* *}$ Intact PTH (normal $<65$ pg/ml).

\section{Discussion}

During the course of the study 538 patients underwent operations for parathyroid pathology and 5663 for thyroid pathology in our department thus there were just over 6000 cervicotomies for cervical, endocrine pathology. Parathyroid cysts account for $4.6 \%$ of parathyroid pathologies managed surgically and $0.41 \%$ of cervicotomies carried out. Our sample is representative of the literature with a predominence of female subjects (sex ratio $=3.2$ ), patients in the fourth and fifth decade are most commonly affected [5,6].

Generally parathyroid cysts present with a solitary lesion at the laterocervical base [7-9] and preferentially localise to the left $[1,9]$. Most commonly there is a solitary, uninodular lesion; however Delaunay et al. raised the possibility of multiple cysts in 3\% of cases [1]. Multinodular cysts have also been described relating to cysts within adenomas [2]. On average the size of cysts varies between 3 and $5 \mathrm{~cm}$ [7] with a fluid content between 2 and $75 \mathrm{ml}$ [10]. Mediastinal cysts have been described with a size of up to $12 \mathrm{~cm}$ [11]. Many hypotheses have been suggested to explain the development of parathyroid cyst: degeneration or bleeding of the parathyroid gland or an adenoma which forms active cysts in the parathyroid cell wall $[7,8]$ development of embriological residuals $[12,13]$ retention of the secretions of the colloid vesicles or enlargement of microcysts by retention [14] forming inactive cysts with a clear liquid.

The circumstances of discovery are variable. It can be a chance discovery on examination with the suspicion of thyroid pathology (goiter, nodule) or other cervical mass (carotid vessels, adenopathies etc.) or during surgery in the area concerned [2,15] (14 in our observation). Elsewhere examination will note a palpable anterior cervical mass $[2,16]$ or laterocervical base masses $[15,17]$ which is smooth, renitent and mobile presenting like a thyroid nodule. The cervico-mediastinal cysts can give the impression of a plunging goitre [11]. This mass can appear serious if associated with pain (raising suspicion of a haemorrhagic complication). The diagnosis is eventually considered with associated hypercalcemia [18]. You will not find adenopathy in our study.
Typically these cysts, even those discovered in association with cervical mass conditions, are asymptomatic. Rarely there are clinical signs corresponding to a complication: cervical pain $[1,3,11,19]$ and/or thoracic pain [18] or compression symptoms [3,8,11,16,18-20], dyspahgia (one of our observations), dysphonia [5,20] dyspnoea, dry cough or stridor $[15,21]$ deviation and vascular compression $[11,18,22]$. Systemically the patient will be normal unless the cyst causes significant hyperparathyroidism which itself can be symptomless.

Parathyroid cysts can be functional and secretary, causing hyperparathyroidism in $10 \%-15 \%$ of cases $[3,5,20,23], 20 \%$ in our trial. Only $1 \%-5 \%$ of cases of hyperparathyroidism are caused by parathyroid cysts (in our experience there were five FPCs every 538 cervicotomies for parathyroid pathology, 0.9\%) FPCs, most frequently encountered in male patients, are typically degenerative or are bleeds from an adenoma [14,16,21]. Their content is brownish or bloody [1]. The cyst does not have a clear epithelial wall and is lined with parathyroid tissue $[1,4,14]$. Thus they are pathologically recognisable.

It is not misleading to describe inactive or non-functional cysts as parathyroid. They contain a clear mucous fluid $[1,11,13]$. Parathyroid tissue is found on histological examination forming islands surrounded by fibrous tissue, this confirms the parathyroid nature of the cyst $[1,11,14,20,21]$.

Associations have been noted with other parathyroid pathologies (hyperplasia (1case), adenoma of another parathyroid gland responsible for hyperparathyroidism [2, 13] 3 of our observations) or can be incidental findings in thyroid disease [24].

One of our observations concerned a mediastinal cyst. Its localisation has been widely reported in the literature where 94 of 250 cysts listed were parathyroid [11] meaning that the incidence of mediastinal glands is between $2.5 \%$ - 22\% [10,17,19,22]. The cysts (active in $42 \%$ of cases [2]) are most often situated anterior to the mediastinum (82\%) where they occur as cysts on inferior ectopic glands.

Imaging —in particular ultrasound —only confirms the 
cystic nature of the lesion without differentiating between parathyroid cysts and other types of cysts $[17,25]$. On fine needle aspiration the fluid colour is variable: clear like mineral water (nearly always pathogenic of a parathyroid cyst [5] or milky, bloody etc. (suggestive of a thyroid cyst $[5,6]$ ) The presence of parathyroid hormone (PTH) in the aspirate fluid confirms the parathyroid nature of the cyst $[2,11,12,25]$ but does not allow a ruling on the activity level of the cyst because the PTH concentration in the cystic fluid can be greater than the PTH concentration in the blood in either type of cyst (FPCs or NFPCs) [6,25]. Only blood biochemistry can tell the difference between FPCs or NPCs. For some, the concentration of carboxyterminel fragments of PTH in the aspirate fluid is more interesting and a better measure than the whole hormone $[2,11,21,26]$. The aspirate fluid of parathyroid cyst is acellular and does not contain thyroid hormones.

Fine Needle Aspiration allows the diagnosis between rarer parathyroid cysts and thyroid cysts, which are often falsely suspected, to be made $[5,8,17,20,23]$. In thyroid cysts the intracystic level of thyroid hormones and thyroglobulin is raised while the level of PTH is zero $[8,20,27]$.

Aside from their diagnostic role, ultrasound guided FNA can treat cysts by drainage but recurrence is always a possibility (one of our observations). In these cases surgery $[3,8,20,22,28]$ repeated fine needle aspiration until the cyst disappears $[1,2,23]$ or intracystic injections to cause sclerosis (tetracycline [27] or ethanol [3,4]) can then be considered. Intracystic injections are accompanied by pain, fever and transient breathlessnesss in $5 \%$ of cases $[4,6,20]$. This technique presents risks of pericystic fibrosis (especially with ethanol injections) which can lead to recurrence of the cyst [3]. It is for this reason that Verges et al. advise that whilst carrying out the technique one should speak to the patient and, at the slightest suggestion of dysphonia, should stop the procedure (4 transient dysphonias out of 13 patients in their trial) [29]. It appears that recovery can be established without the need for subsequent sclerosing injections $[27,28]$.

In a study of 37 patients Ippolito et al. [25] treated 14 patients by fine needle aspiration (FNA). There were 4 recurrences, all of them treated by surgery. They concluded, FNA is diagnostic due to the characteristic appearance of the fluid and high PTH levels but can also be curative. However recurrences exist and will have to be treated by surgery [25].

In the context of an active parathyroid cyst surgical excision seems the obvious choice $[1,2,5,7,13,27]$ with an extemporaneous histological examination of the surgical specimen. This dissection can be difficult due to the hypervascular character of the cyst and the fact that it can be embedded in the thyroidal parenchyma which can lead to associated resection of the thyroid gland [30]. The three remaining parathyroid glands must also be explored to look for double localisations and associations; however some suggest that it may be sufficient to only explore the unilateral parathyroid gland [30]. Severe hypercalcemia indicates a fine needle aspiration in order to treat the hypercalcemia [1], primary sclerotherapy [29] can permit a secondary surgical removal with the patient in a better metabolic state. The intervention can be guided by the perioperative PTH levels.

\section{Conclusion}

The indications for surgical or radiological interventions essentially depend on whether or not the cyst is active and on its localisation which determines the possibility of fine needle aspiration. True PCs are non functional. Post therapeutic surveillance of calcium levels is a necessary requirement for the early detection of a recurring cyst or other parathyroidal pathology.

\section{REFERENCES}

[1] T. Delaunay, C. Peillon and J. L. Manouvrier, "Parathyroid Cyst. A Report of Six Cases,” Annales de Chirurgie, Vol. 44, No. 3, 1990, pp. 231-235.

[2] S. Nozeran, M. Duquenne, S. Guyetant, P. Rodien, V. Rohmer and J. Ronceray, "Diagnosis of Parathyroid Cyst: Importance of Dosage of Parathyroid Hormone in the Aspirated Fluid,” Presse Medicale, Vol. 29, No. 17, 2000, pp. 939-941.

[3] M. Akel, I. Salti and S. T. Azar, "Successful Treatment of Parathyroid Cyst Using Ethanol Sclerotherapy,” American Journal of the Medical Sciences, Vol. 317, No. 1, 1999, pp. 50-52. doi:10.1097/00000441-199901000-00007

[4] M. Zingrillo, M. R. Ghiggi and A. Liuzzi, “A Large Functioning Parathyroid Cyst Recurring after Aspiration and Subsequently Cured by Percutaneous Ethanol Injection,” Journal of Clinical Ultrasound, Vol. 24, No. 7, 1996, pp. 378-382. doi:10.1002/(SICI)1097-0096(199609)24:7<378::AID-JC $\underline{\mathrm{U} 10>3.0 . \mathrm{CO} ; 2-\mathrm{D}}$

[5] D. D. Lydiatt, R. M. Byers, K. G. Khouri, P. W. Whitworth and R. V. Sellin, "Functional Parathyroid Cyst and Hypocalciuric Hypercalcemia,” Ear, Nose, \& Throat Journal, Vol. 72, No. 2, 1993, pp. 713-716.

[6] A. J. De Raimo, R. A. Kane, J. F. Katz and A. P. Rolla, "Parathyroid Cyst: Diagnosis by Sonography and Needle Aspiration," American Journal of Radiology, Vol. 142, No. 6, 1984, pp. 1227-1228.

[7] D. Safran, "Functioning Parathyroid Cyst," South Medical Journal, Vol. 91, No. 10, 1998, pp. 978-980. doi:10.1097/00007611-199810000-00018

[8] E. Garin, F. Le Gall, H. Sevestre and G. Leclech, "Latent Forms of Parathyroïd Cysts. Report of Two Cases,” Annals de Pathologie, Vol. 14, No. 6, 1998, pp. 415-418. 
[9] M. B. Ujiki, R. Nayar, C. Sturgeon and P. Angelos, "Parathyroid Cysts: Often Mistaken for a Thyroid Cyst,” World Journal of Surgery, Vol. 31, No. 1, 2007, pp. 60-64. doi:10.1007/s00268-005-0748-8

[10] W. R. Jarnagin and O. H. Clark, "Mediastinal Parathyroid Cyst Causing Persistent Hyperparathyroidism: Case Report and Review of the Literature," Surgery, Vol. 123, No. 6, 1998, pp. 709-711. doi:10.1016/S0039-6060(98)70213-2

[11] T. W. Shields and S. C. Immerman, "Mediastinal Parathyroid Cysts Revisited," The Annals of Thoracic Surgery, Vol. 67, No. 2, 1999, pp. 581-590. doi:10.1016/S0003-4975(99)00018-1

[12] A. F. Spitz, "Management of a Functioning Mediastinal Parathyroid Cyst," Journal of Clinical Endocrinology and Metabolism, Vol. 80, No. 10, 1995, pp. 2866-2888. doi:10.1210/jc.80.10.2866

[13] V. L. Van Fossen and A. J. Edis, "Clear Parathyroid Cysts and Hyperparathyroidism," The American Surgeon, Vol. 64, No. 12, 1998, pp. 1226-1228.

[14] D. B. Calandra, K. H. Shah, R. A. Prinz, H. Sullivan, C. Hofmann, R. Oslapas, K. Ernst, A. M. Lawrence and E. Paloyan, "Parathyroid Cyst: A Report of Eleven Cases Including Two Associated with Hyperparathyroid Crisis," Surgery, Vol. 94, No. 6, 1983, pp. 887-892.

[15] A. T. Gurbuz and M. E. Peetz, "Giant Mediastinal Parathyroid Cyst: An Unusual Cause of Hypercalcemic Crisis-Case Report and Review of the Literature,” Surgery, Vol. 120, No. 5, 1996, pp. 795-800. doi:10.1016/S0039-6060(96)80086-9

[16] C. R. Hughes, B. Kanmaz, A. T. Isitman, G. Akansel, T. Lawson and B. D. Collier. "Misleading Imaging Results in the Diagnosis of Parathyroid Cysts," Clinical Nuclear Medicine, Vol. 19, No. 5, 1994, pp. 422-425. doi:10.1097/00003072-199405000-00010

[17] B. Petitjean, “A Cervical Cyst,” Annales de Pathologie, Vol. 20, No. 3, 2000, pp. 273-274.

[18] K. J. Simic, M. T. Mc Dermott, G. J. Crawford, W. H. Marx, J. L. Ownbey and G. S. Kidd. "Massive Extracapsular Heamorrhage from a Parathyroid Cyst," Archives of Surgery, Vol. 124, No. 11, 1989, pp. 1347-1350. doi:10.1001/archsurg.1989.01410110109023

[19] W. M. Lydiatt, A. R. Shaha, I. Munshi and R. Robbins. "Giant Mediastinal Cyst Masquerading as a Substernal Goiter,” Otolaryngology_Head and Neck Surgery, Vol. 116, No. 3, 1997, pp. 411-413. doi:10.1016/S0194-5998(97)70285-7
[20] A. Alvi, D. Myssiorek and P. Wasserman. "Parathyroid Cyst: Current Diagnostic and Management Principles," Head and Neck, Vol. 18, No. 4, 1996, pp. 370-373. doi:10.1002/(SICI)1097-0347(199607/08)18:4<370::AID -HED8>3.0.CO;2-V

[21] O. Landau, D. W. Chamberlain, R. S. Kennedy, F. G. Pearson and S. Keshavjee, "Mediastinal Parathyroid Cysts," The Annals of Thoracic Surgery, Vol. 63, No. 4, 1997, pp. 951-953. doi:10.1016/S0003-4975(96)01392-6

[22] V. T. de Montpreville, "Mediastinal Parathyroid Cysts," The Annals of Thoracic Surgery, Vol. 63, No. 4, 1997, pp. 951-953.

[23] B. Mitmaker, S. Lerman, E. Lamoureux and L. Begin, "Parathyroid Cyst: Diagnosis and Treatment of an Unusual Surgical Problem," Canadian Journal of Surgery, Vol. 34, No. 1, 1991, pp. 59-61.

[24] E. G. Lever, S. Refetoff, F. H. Straus 2nd, M. Nguyen and E. L. Kaplan, "Coexisting Thyroid and Parathyroid Disease-Are They Related?” Surgery, Vol. 94, No. 6, 1983, pp. 893-900.

[25] G. Ippolito, F. Fausto Palazzo, F. Sebag, M. Sierra, C. De Micco and J. F. Henry, “A Single Institution 25-Year Review of True Parathyroid Cysts,” Langenbeck's Archives of Surgery, Vol. 391, No. 1, 2006, pp. 13-18. doi:10.1007/s00423-005-0579-y

[26] B. C. Jha, N. M. Nagarkar, S. Kochhar, H. Mohan and A. Dass, "Parathyroid Cyst: A Rare Cause of Anterior Neck Mass,” The Journal of Laryngology and Otology, Vol. 113, No. 1, 1999, pp. 73-75. doi:10.1017/S0022215100143208

[27] A. Sanchez and H. Carretto, "Treatment of Non-Functioning Parathyroid Cyst with Tetracycline Injection,” Head \& Neck, Vol. 15, No. 3, 1993, pp. 263-265. doi:10.1002/hed.2880150317

[28] B. Shi, H. Guo and N. Tang, "Treatment of Parathyroid Cysts with Fine Needle Aspiration,” Annals of Internal Medicine, Vol. 131, No. 10, 1999, pp. 797-798.

[29] B. L. Verges, J. P. Cercueil, D. Jacob, G. Vaillant, J. M. Brun and R. Putelat, "Results of Ultrasonically Guided Percutaneous Ethanol Injection into Parathyroid Adenomas in Primary Hyperparathyroidism,” The Lancet, Vol. 337, No. 8754, 1991, pp. 1421-1422. doi:10.1016/0140-6736(91)93115-P

[30] P. C. Chaffanjon, N. Cardin, O. Chabre and P. Y. Brichon, "Parathyroid Cyst," Annales de Chirurgie, Vol. 126, No. 5, 2001, pp. 456-458. doi:10.1016/S0003-3944(01)00530-2 